\title{
Trastornos de la marcha como predictor de demencia no Alzheimer
}

Abnormality of Gait as a predictor of Non-Alzheimer's Dementia. Verghese J, Lipton RB, Hall CB, Kuslansky G, Katz MJ and Buschke H. N Engl J Med 2002; 347: 1761-1768.

\section{Objetivo}

Determinar si los trastornos de la marcha en ancianos, sin trastornos cognitivos en el análisis basal, son predictores del desarrollo de demencia.

\section{Diseño}

Estudio de cohorte prospectivo, conducido entre 1980 y 1983 con un seguimiento hasta 2001.Bronx Aging Study.

\section{Lugar}

Ciudad de Nueva York (EE.UU.).

\section{Participantes}

Un total de 488 sujetos mayores de 75 años al inicio del estudio fueron incluidos luego del primer examen en que se determinó que estaban sin demencia.Fueron excluidos los que poseían antecedentes de Enfermedad de Parkinson, alcoholismo o enfermedades en estadio terminal.Los sujetos fueron seguidos por un periodo 7 años con visitas regulares cada 12 meses, quedando en el estudio 422 ancianos.

\section{Resultados Principales}

En el análisis basal 85 participantes poseían trastornos de la marcha que fueron calificadas como:marcha inestable, marcha frontal, marcha hemiparética, marcha neuropática, marcha atáxica, marcha parkinsoniana y marcha espástica
Durante 7 años de seguimiento, 125 sujetos desarrollaron demencia, de los cuales 70 reunían criterios de Enfermedad de Alzheimer (EA) y 55 de Demencia no Alzheimer (47 con Demencia Vascular y 8 con otros tipos de demencia).

Los riesgos relativos se expresan en la Tabla 1.Los sujetos con alguna alteración neurológica en la marcha tuvieron un riesgo elevado de desarrollar Demencia en general, sobre todo Demencia no Alzheimer y con mayor poder predictor para el desarrollo de Demencia Vascular.

\section{Tabla 1}

\begin{tabular}{l|c|l|l|l}
\hline $\begin{array}{l}\text { Tipos de trastornos } \\
\text { de la Marcha }\end{array}$ & $\mathbf{N}^{\circ}$ de Sujetos & $\begin{array}{l}\text { Todas las } \\
\text { Demencias }\end{array}$ & $\begin{array}{l}\text { Demencia } \\
\text { No Alzheimer }\end{array}$ & $\begin{array}{l}\text { Demencia } \\
\text { Vascular }\end{array}$ \\
\hline Todos & 85 & $1.9(1.3-3)$ & $3.5(2-6.2)$ & $5.5(1.9-6.4)$ \\
\hline Inestable & 31 & $1.7(0.9-3)$ & $2.4(1.1-5.2)$ & $2.6(1.1-6)$ \\
\hline Fontal & 12 & $2.4(0.8-6.6)$ & $3.5(1.0-11.5)$ & $4.3(1.3-15)$ \\
\hline Hemiparética & 11 & $5.5(2.5-12.6)$ & $11.7(4.5-30.5)$ & $13.1(4.8-35.8)$ \\
\hline Neuropática & 11 & $0.9(0.3-3)$ & $0.7(0.9-5)$ & $0.8(0.1-6)$ \\
\hline Atáxica & 10 & $0.9(0.3-2.7)$ & $0.6(0.1-4.8)$ & $0.6(0.1-4.5)$ \\
\hline
\end{tabular}

\section{Conclusiones}

Lo presencia de trastornos de la marcha en ancianos sin demencia fue un potente predictor del desarrollo de demencias en general y sobre todo de Demencia Vascular.

\section{Comentario}

Los trastornos de la marcha son un problema prevalente en los ancianos como también lo son los trastornos de la memoria y las demencias. Las consecuencias más reconocidas de los problemas de la marcha son las caídas repetidas y el miedo a deambular, acompañado de una marcha inestable persistente ${ }^{1,2,3}$. La marcha anormal en ancianos puede ser producida por enfermedades neurológicas y /o por enfermedades sistémicas prevalentes tan disímiles como la osteoartrosis o la Insuficiencia Cardíaca. Este trabajo es interesante, porque muestra que en una cohorte de ancianos de la comunidad, libres de demencia en el análisis basal, aquellos con trastornos neurológicos de la marcha tuvieron mayor riesgo de desarrollar demencia. La presencia de una marcha patológica predijo fuertemente demencias en general y en particular el desarrollo de Demencia Vascular, pero no predijo de manera estadísticamente significativa la Enfermedad de Alzheimer. Con un seguimiento prospectivo y regular (promedio 7 años), han podido demostrar en que todos los trastornos de la marcha (hemiparético, frontal, atáxico e inestable) fueron predictores de demencia.Curiosamente el patrón de marcha inestable, que no había sido previamente asociado a los trastornos de daño cerebrovascular fue un potente predictor de Demencia Vascular (ver Tabla 1). Los riesgos relativos se mantuvieron, aún luego del ajuste por variables demog ráficos, de comorbilidad y cognitivas.

Es interesante analizar porque problemas precoces de la marcha podrían predecir el desarrollo de demencia con un hiato libre de enfermedad prolongado. De acuerdo a los criterios que definen los diferentes tipos de demencia, es aceptado que la presencia inicial de trastornos de la marcha aleja el diagnóstico de EA, mien- tras que acerca y hace más probable el diagnóstico de otras demencias como las vasculares o la asociada a cuerpo de Lewy. Los autores proponen como hipótesis que cambios sutiles en la marcha por un daño cerebral mínimo podría producir tempranamente una marcha anormal, que sólo mucho después se manifestaría como demencia.

Es útil recordar, que los problemas de la marcha en los ancianos poseen diferentes orígenes y generalmente son poli causales. La clasificación más aceptada para poder analizarlos es la propuesta por Nutt y colaboradores, que los divide en tres jerarquías según el nivel sensoriomotor afectado, incluyendo de esta manera, no sólo enfermedades neurológicas sino también a trastornos osteomusculares como la osteoartrosis ${ }^{4}$.

Con respecto a como se clasificaron y evaluaron los problemas de la marcha en este trabajo, hubiera sido interesante que además de utilizar un criterio clínico de clasificación, hubieran utilizado un análisis cuantitativos. Por ejemplo, existe evidencia que medida tan simples como la Velocidad de la Marcha (VM) predicen eventos adversos tales como caídas, fracturas, hospitalización, institucionalización y muerte ${ }^{5,6,7,8}$.Éstos descubrimientos, con respecto al análisis de la marcha en ancianos, podrían proveer una estrategia para identificar grupos con alto riesgo en población de ancianos, en este caso para el desarrollo de demencias, sobre todo Demencia Vascular.

En conclusión, este estudio muestra con aceptable evidencia (estudio de cohorte - grado II 2b) que la presencia de una marcha anormal de origen neurológico en pacientes sin demencia, los coloca en un grupo de riesgo para desarrollar Demencia no Alzheimer y en particular Demencia Vascular.

\section{Dr. Manuel Montero-Odasso}

[ Vicedirector Carrera de Especialistas en Geriatría.Servicio de Clínica Médica y Sección Geriatría. Hospital Italiano de Buenos Aires ]

\section{Referencias}

1.Sudarsky L.Geriatrics:gait disorders in the elderly.N Engl J Med 1990;322:1441-1446.

2.Alexander NB.Differential diagnosis of gait disorders in older adults. Clin Geriatr Med 1996;12:689-703.

3.Fuh J-L, Lin KN, Wang SJ, Ju TH, Chang R, Liu H-C.Neurologic diseases presenting with gait impairment in the elderly.J Geriatr Psychiatry Neurol 1994;7:89-92.

4.Nutt JG, Marsden CD, Thompson PD. Human walking and higher-level gait disorders, particularly in the elderly.Neurology 1993;43:268-279.

5.Montero-Odasso M, Schapira M, Varela M et al.Gait Velocity as an easy test to detect mobility impairment.J.Am Geriatric Soc 2001;49:296.

6.Guralnick JM, Ferruci L, Simonsick EM et al.Lower extremity function in persons over the age of 70 years as a predictor of subsequent disability.N Engl J Med 1995;332:556-561.

7.Montero-Odasso M, Schapira M, Varela M et al."Gait Velocity as a predictor of adverse events in non disabled elderly.J Am Geriatric Soc 2003;51:477.

8.Studenski S, Perera S, Wallace D et al.Physical performance measures in the clinical setting.J Am Geriatr Soc 2003;51:314-22. 